\title{
Effect of solution treatment on spinodal decomposition during aging of an Fe-46.5 at.\% Cr alloy
}

\author{
Jing Zhou ${ }^{1,2}$, Joakim Odqvist ${ }^{1}$, Andrei Ruban ${ }^{1}$, Mattias Thuvander ${ }^{3}$, Wei Xiong ${ }^{4}$, \\ John Ågren ${ }^{1}$, Gregory B. Olson ${ }^{4}$, and Peter Hedström ${ }^{1, \star}$ (i) \\ ${ }^{1}$ Department of Materials Science and Engineering, KTH Royal Institute of Technology, 10044 Stockholm, Sweden \\ ${ }^{2}$ Atlas Copco Rock Drills AB, 70191 Örebro, Sweden \\ ${ }^{3}$ Department of Applied Physics, Chalmers University of Technology, 41296 Göteborg, Sweden \\ ${ }^{4}$ Department of Materials Science and Engineering, Northwestern University, Evanston, IL 60208-3109, USA
}

Received: 26 May 2016

Accepted: 23 August 2016

Published online:

7 September 2016

(C) The Author(s) 2016. This article is published with open access at Springerlink.com

\begin{abstract}
Spinodal decomposition is a key phase transition in advanced materials and a significant effort is paid to the quantitative modeling of the phenomenon. The initial materials condition is often assumed to be random during modeling, but this may be an oversimplification. In this work, the effect of solution treatment above the miscibility gap, on spinodal decomposition during subsequent aging, has been investigated for an Fe-46.5 at.\% $\mathrm{Cr}$ alloy. By atom probe tomography (APT), it is found that different extents of quenched-in Cr clustering exist after solution treatments at different temperatures. The clustering is pronounced at $800{ }^{\circ} \mathrm{C}$ but decreases significantly with increasing temperature to $900{ }^{\circ} \mathrm{C}$. Thermodynamic Monte Carlo simulations show that there is a difference in atomic short range order between the different solution treatment temperatures. By APT, it is, furthermore, found that the kinetics of spinodal decomposition at $500{ }^{\circ} \mathrm{C}$, i.e., within the miscibility gap, is enhanced in the initial alloy condition, where $\mathrm{Cr}$ was less randomly distributed. These observations are supported by kinetic Monte Carlo simulations, predicting a similar but less pronounced qualitative effect on spinodal decomposition kinetics. Other possible reasons for the enhanced kinetics could be related to clustering of interstitial elements and/ or sigma phase, but neither was found in the experiments. Nonetheless, the observations in this work suggest that it is necessary to implement a modeling strategy, where the initial structure is properly accounted for when simulating spinodal decomposition.
\end{abstract}

Address correspondence to E-mail: pheds@kth.se 


\section{Introduction}

Stainless steels are desirable in numerous engineering applications due to their high corrosion resistance and attractive mechanical properties. However, the stainless steels containing the body centered cubic or tetragonal $(\mathrm{bcc} / \mathrm{bct})$ phase, i.e., ferrite or martensite, are susceptible to phase separation and a corresponding embrittlement phenomenon traditionally called ' $475{ }^{\circ} \mathrm{C}$ embrittlement'. This embrittlement, originating from the $\mathrm{Fe}-\mathrm{Cr}$ binary system, limits the service temperature range and restricts the introduction of these alloys in certain applications, where fracture could lead to catastrophic consequences, e.g., within nuclear power generation. The phase separation induced during low-temperature aging will cause a demixing of the alloying elements $\mathrm{Fe}$ and $\mathrm{Cr}$, which can occur via two different mechanisms, viz., spinodal decomposition or nucleation and growth $[1,2]$. The coherency strains generated between the Fe-rich $(\alpha)$ and Cr-rich $\left(\alpha^{\prime}\right)$ domains cause hardening [3], which presumably leads to the embrittlement. Furthermore, it has been reported that, e.g., solute clustering [4], C segregation [5], and G-phase formation $[6,7]$ could also contribute to the embrittlement in $\mathrm{Fe}-\mathrm{Cr}$-based multicomponent alloys.

The scientific interest in phase separation in $\mathrm{Fe}-\mathrm{Cr}$ alloys has grown in recent years due to the importance of these alloys in current and future power generation applications [8]. Much work has been devoted to the development of models able to predict spinodal decomposition via, e.g., phase-field modeling solving the Cahn-Hilliard equation $[9,10]$ or via kinetic Monte Carlo simulations [11, 12]. In most of these modeling studies, the initial structure is assumed to be random. However, it is known that the thermal history of the alloy plays a role for the subsequent aging kinetics. For instance, it has been shown that the cooling rate after solution treatment is important [13-16] and a few reports point out the effect of the solution treatment temperature on the subsequent phase decomposition [17, 18]. Vintaykin et al. [17] investigated the kinetics of decomposition after solution treatments at different temperatures in the range from 600 to $1300{ }^{\circ} \mathrm{C}$. They showed, using small-angle neutron scattering, that the rate of decomposition was higher for lower solution treatment temperatures. They did not present any experimental results for the initial structure, but discussed that the reason behind the difference could be concentration fluctuations in the solution-treated condition. LaSalle and Schwartz [18] investigated two different solution treatment temperatures of 850 and $1200{ }^{\circ} \mathrm{C}$ and also found that the lower temperature gave faster decomposition upon subsequent aging. Furthermore, it has been found, both theoretically and experimentally, that there is a positive atomic short range order (SRO), i.e., clustering, above the miscibility gap in concentrated $\mathrm{Fe}-\mathrm{Cr}$ alloys above about 10 at.\% Cr [19-23]. Recently, Zhou et al. [24] have reported atom probe tomography (APT) observations of the clustering of $\mathrm{Cr}$ in the bcc phase of ferritic and duplex stainless steels after solution treatment. Zhou et al. [25] further showed that the clustering of $\mathrm{Cr}$ in a binary $\mathrm{Fe}-46.5$ at.\% $\mathrm{Cr}$ alloy decreases with increasing solution treatment temperature above the miscibility gap from 800 to $900{ }^{\circ} \mathrm{C}$. These experimental results were corroborated by the Monte Carlo simulations of the SRO above the miscibility gap. However, no results have been presented linking the SRO above the miscibility gap, clustering of $\mathrm{Cr}$ in solution-treated alloys, and the effect on spinodal decomposition. The above directly motivates the present research using an integrated approach of designed key experiments and structure modeling. An Fe-46.5 at.\% Cr alloy is solution-treated at 800 and $900{ }^{\circ} \mathrm{C}$ and quenched. Thereafter, aging at $500{ }^{\circ} \mathrm{C}$ for up to $1000 \mathrm{~h}$ is conducted and the behavior is evaluated using hardness measurements and APT. Furthermore, thermodynamic and kinetic Monte Carlo is performed.

\section{Methodology}

\section{Experiments}

The chemical composition of the investigated alloy was Fe-46.5Cr-0.53Si-0.08Mn-0.03Ni-0.001C (at.\%). Small specimens of $4 \times 4 \times 30 \mathrm{~mm}^{3}$ were cut to try and preserve the high-temperature structure after solution treatment and to avoid phase decomposition during the quenching. Since the critical temperature of the bcc miscibility gap in the $\mathrm{Fe}-\mathrm{Cr}$ system is about $700{ }^{\circ} \mathrm{C}$, according to [26], the specimens were solution-treated at 800 and $900{ }^{\circ} \mathrm{C}$ for $24 \mathrm{~h}$ and subsequently quenched in brine. These treatments were performed to "homogenize" the ferrite and it should be mentioned that ferrite may be metastable at these temperatures, especially at $800{ }^{\circ} \mathrm{C}$, where sigma 


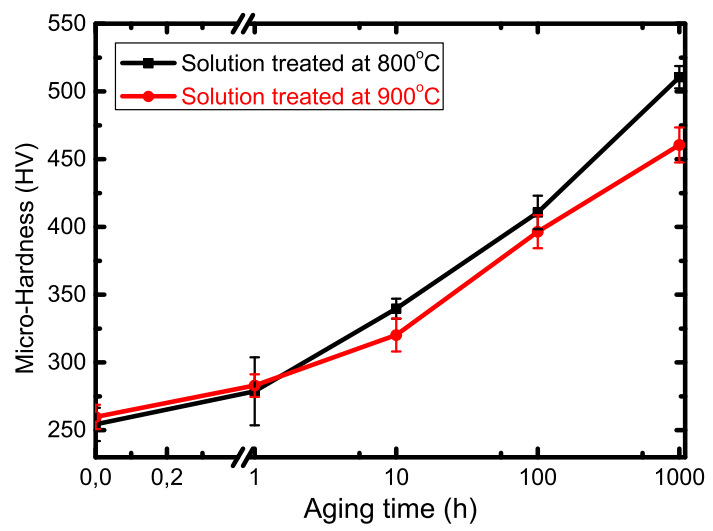

Figure 1 Micro-hardness evolution with aging time at $500{ }^{\circ} \mathrm{C}$ for two different initial conditions, i.e., different solution treatment temperatures of 800 and $900{ }^{\circ} \mathrm{C}$.

phase may be the equilibrium phase. However, the formation of the sigma phase has been reported to be very sluggish and the few small sigma particles that may form were believed to have a minor effect.

The aging was conducted at $500{ }^{\circ} \mathrm{C}$ for $1,10,100$, and $1000 \mathrm{~h}$. Thereafter, all specimens were investigated using micro-Vickers hardness measurements and a load of $100 \mathrm{~g}$. Ten measurements per condition were taken.

The specimens for the APT analysis were first cut into blanks with the size of $0.3 \times 0.3 \times 20 \mathrm{~mm}^{3}$. Thereafter, final-tip sharpening was performed by the standard two-step electro-polishing method. The analysis was conducted using a local electrode atom probe (LEAP 3000X $\mathrm{HR}^{\mathrm{TM}}$, Imago Scientific Instruments). The voltage-pulsing mode was used, and the measurement parameters were: temperature $50 \mathrm{~K}$, pulse fraction $20 \%$, pulse frequency $200 \mathrm{kHz}$, and evaporation rate $1.5 \%$. The reconstructions were performed using the software IVAS 3.4 .3 with a geometrical field factor of 3.8 and an image compression factor of 1.80 . With these parameters, the decomposed microstructures became isotropic, in accordance with the expectations [27].

The statistical evaluation of the data was performed by the frequency diagram (FD) analysis [28], using a sampling bin size of 50 ions, and by the radial distribution function (RDF) analysis, which has been proven to be very sensitivity to clustering and the early stages of phase separation. The normalized RDF was constructed from the APT data according to the following equation [29].

$\operatorname{RDF}(r)=\sum \frac{C_{E}(r)}{C_{0}}=\sum \frac{N_{E}(r) / N(r)}{C_{0}}$.

Here, $C_{E}(r)$ is the atomic composition of element $E$ at a distance of $r, C_{0}$ is the average composition of element $E$ in the analyzed volume, $N_{E}(r)$ is the total number of atoms of element $E$ at $r$, and $N(r)$ is the total number of atoms of all elements at $r$. Furthermore, the standard errors (s) for the concentration of element $E$ were estimated according to the following equation [28] and normalized.

$s=\sqrt{N_{E}(r)} / N(r)$.

After constructing the normalized RDFs, the amplitude of phase decomposition could be estimated using the following equation [29].

$2 A=2 C_{0} \sqrt{2(\operatorname{RDF}(0)-1)}$.

Here, $2 A$ is the peak-to-trough amplitude and $\mathrm{RDF}(0)$ is the extrapolated value at $0 \mathrm{~nm}$ distance from the RDF curve, herein the $\mathrm{Cr}-\mathrm{Cr} \mathrm{RDF}$ curve.
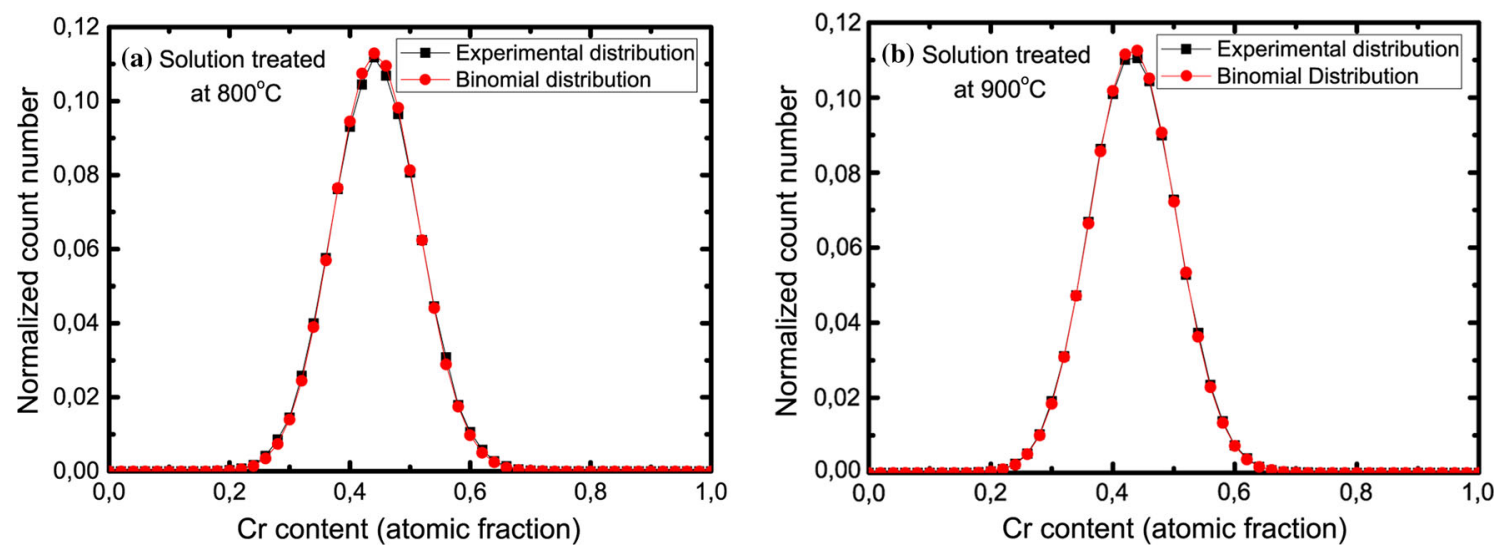

Figure 2 Experimental distribution of $\mathrm{Cr}$ and binomial distribution after solution treatment at $800{ }^{\circ} \mathrm{C}(\mathbf{a})$ and $900{ }^{\circ} \mathrm{C}(\mathbf{b})$. 
Table 1 Reduced $\chi^{2}$, $V$ values, and amplitudes obtained by Eq. (2)

\begin{tabular}{lllllllll}
\hline Solution temperatures $\left({ }^{\circ} \mathrm{C}\right)$ & 800 & & & 900 & \\
\cline { 2 - 3 } Aging time at $500{ }^{\circ} \mathrm{C}(\mathrm{h})$ & 0 & 100 & 1000 & & 0 & 100 & 1000 \\
\hline Reduced $\chi^{2}$ & 8.41 & $1.2 \mathrm{e} 4$ & $2.8 \mathrm{e} 6$ & & 3.69 & $3.2 \mathrm{e} 3$ & $2.5 \mathrm{e} 5$ \\
V & 0.022 & 0.52 & 1.18 & & 0.013 & 0.21 & 0.77 \\
Peak-to-trough amplitude (at.\%) & - & 42.3 & 73.3 & & - & 25.1 & 53.2 \\
\hline
\end{tabular}

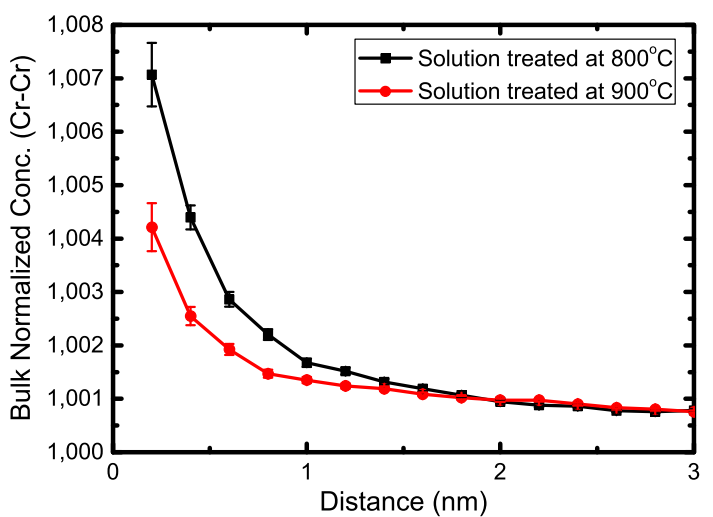

Figure $3 \mathrm{Cr}-\mathrm{Cr}$ RDF curves for unaged specimens of different conditions.

\section{Atomic-scale simulations}

Thermodynamic and kinetic Monte Carlo simulations for an $\mathrm{Fe}_{53.5} \mathrm{Cr}_{46.5}$ bcc alloy were performed. Theoretical effective interactions from [21] were used, except for in the first two interactions at the nearest neighbor and next nearest coordination shell. These interactions were instead taken from an experimental study by Reinhard et al. [30] to be as close as possible to the experimentally observed configurational thermodynamics. To reduce the effect of the periodic boundary conditions, the size of the simulation box was chosen to be $100 \times 100 \times 100$ for the cubic (2atom) unit cell, i.e., containing $2 \times 10^{6}$ atoms.

\section{Results and discussion}

\section{Experimental analysis}

The hardness after solution treatment and aging at $500{ }^{\circ} \mathrm{C}$ is presented in Fig. 1 . The hardening evolution of the two initial alloy conditions, i.e., solutiontreated at 800 and $900{ }^{\circ} \mathrm{C}$, is rather similar initially, but after $1000 \mathrm{~h}$ of aging at $500{ }^{\circ} \mathrm{C}$, there is a distinguishable higher hardness of the alloy that was initially solution-treated at $800{ }^{\circ} \mathrm{C}$. This indicates that the kinetics of spinodal decomposition is faster for that alloy condition. Sigma-phase formation could be another reason for increasing hardness upon aging, but the aging temperature is below the stability region for the sigma phase according to thermodynamic calculations and no sigma phase could be observed in the experimental analysis.

Figure $2 \mathrm{a}, \mathrm{b}$ shows the experimental FDs after the initial solution treatment in comparison with the binomial distribution. The reduced $\chi^{2}$ and variation values ( $V$ values) [31] are listed in Table 1 . It is clear that the difference between the experimental FD and the binomial distribution is very small.

The Cr-Cr RDFs for the two solution-treated conditions are presented in Fig. 3, and it is seen that the specimen solution-treated at $800{ }^{\circ} \mathrm{C}$ has a stronger positive interaction of $\mathrm{Cr}$ at short distances compared with the specimen solution-treated at $900{ }^{\circ} \mathrm{C}$. The positive interaction of $\mathrm{Cr}$ was discussed in Zhou et al. [25] and the conclusion was that the clustering of $\mathrm{Cr}$ is more pronounced in the specimen solution-treated at the lower temperature. The origin of the clustering of $\mathrm{Cr}$ was explained as an effect of the positive SRO, i.e., clustering, above the miscibility gap, as determined by APT and supported by the Monte Carlo simulations. The positive SRO has also been determined earlier by Mössbauer spectroscopy [32], but it could be noted that in that work, the experimental SRO parameter for the first coordination shell was positive, whereas for the second coordination shell, it was negative initially, this is different from the theoretical predictions in [25].

For the aged samples, the difference is already distinguishable by visual inspection of the APT data. Figure 4 shows $\mathrm{Cr}$ atom maps for the samples aged for 100 and $1000 \mathrm{~h}$ and it is clear that the sample initially solution-treated at $800{ }^{\circ} \mathrm{C}$ has a more pronounced decomposition after aging than the sample solution-treated at $900{ }^{\circ} \mathrm{C}$.

This interpretation is further strengthened by the corresponding FDs and RDFs that are shown in Fig. $5 a$ and $b$, respectively. The statistical data evaluated from the FDs and RDFs are included in 
Figure 4 Atom maps (slice thickness $5 \mathrm{~nm}$ ) for the sample solution-treated at $800{ }^{\circ} \mathrm{C}$ and aged at $500{ }^{\circ} \mathrm{C}$ for $100 \mathrm{~h}(\mathbf{a})$, solution-treated at $800{ }^{\circ} \mathrm{C}$ and aged at $500{ }^{\circ} \mathrm{C}$ for $1000 \mathrm{~h}(\mathbf{b})$ solution-treated at $900{ }^{\circ} \mathrm{C}$ and aged at $500{ }^{\circ} \mathrm{C}$ for $100 \mathrm{~h}$ (c), and solution-treated at $900{ }^{\circ} \mathrm{C}$ and aged at $500{ }^{\circ} \mathrm{C}$ for $1000 \mathrm{~h}$ (d).
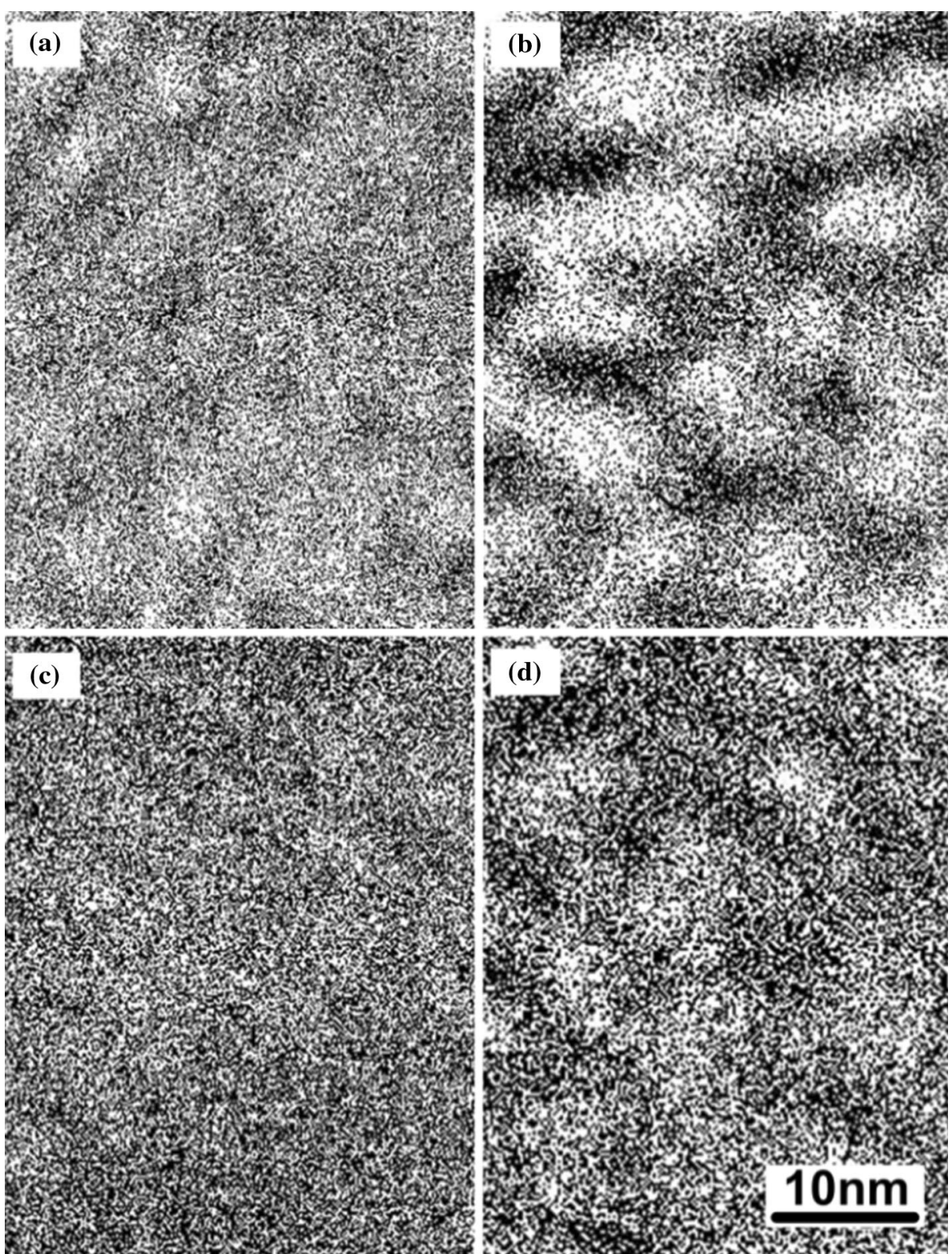

Table 1. From these figures and the statistical data, it is clear that the decomposition after aging is much more pronounced for the sample solution-treated at $800{ }^{\circ} \mathrm{C}$ compared with the sample initially solutiontreated at $900{ }^{\circ} \mathrm{C}$.

The results presented above indicate that the $\mathrm{Cr}$ clustering found after solution treatment increases the kinetics of spinodal decomposition during subsequent aging. However, it should be kept in mind that the effect of other factors, such as interstitial atom clustering and/or sigma-phase formation, cannot be ruled out.

\section{Theoretical analysis}

First, we consider an alloy configuration in the random state above the decomposition temperature. In thermodynamic Monte Carlo simulations, the transition temperature is about $840 \mathrm{~K}\left(567^{\circ} \mathrm{C}\right)$. The behavior of the SRO parameter at the first coordination shell as a function of temperature, $\alpha_{1}(T)$, is presented in Fig. 6. At the point of the phase transition, the function $\alpha_{1}(\mathrm{~T})$ has an inflection point, where its second derivative changes sign. Above the transition, the phase is a random solution with some degree of 
(a)

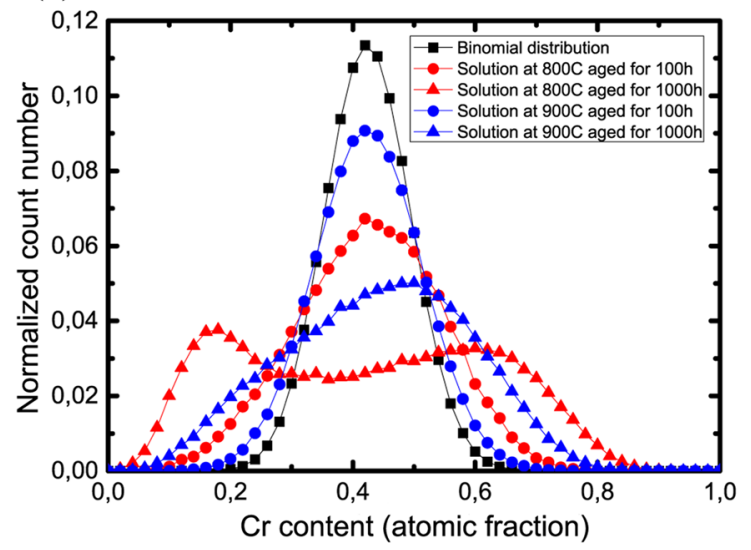

(b)

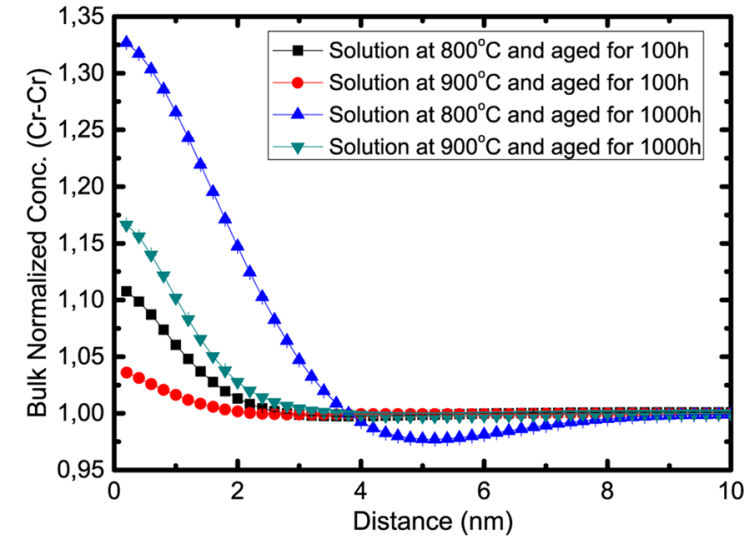

Figure 5 APT representations of specimens with different initial solution treatments subsequently aged at $500{ }^{\circ} \mathrm{C}$ for $100 \mathrm{~h}$ and $1000 \mathrm{~h}$. a Frequency diagrams with binomial distribution and experimental distributions $\mathbf{b}$ normalized $\mathrm{Cr}-\mathrm{Cr} \mathrm{RDF}$ curves.

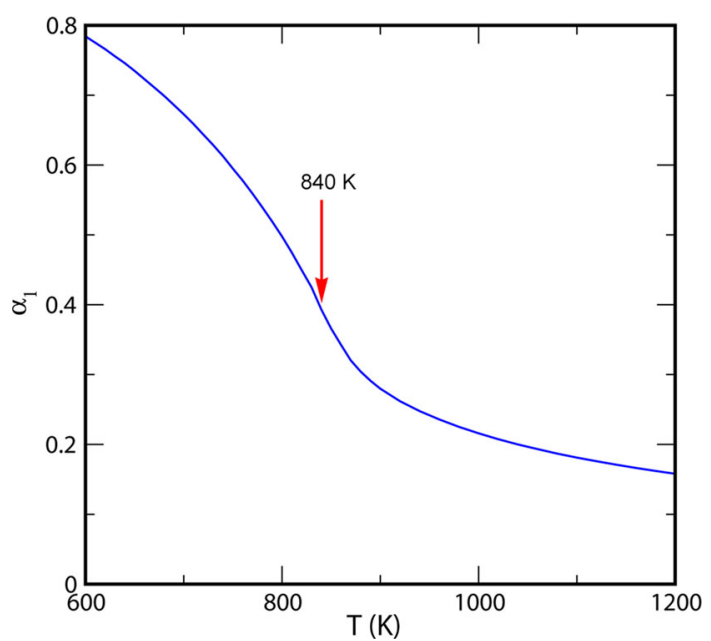

Figure 6 Atomic short range order parameter on the first coordination shell for $\mathrm{Fe}_{53.5} \mathrm{Cr}_{46.5}$ at different temperatures. Red arrow shows an inflection point at the critical temperature of the miscibility gap $840 \mathrm{~K}$.

SRO, and in particular, $\alpha_{1}$ at 800 and $900{ }^{\circ} \mathrm{C}$ are 0.189 and 0.164 , respectively. This means that the structure at both temperatures differs substantially from that of a completely random alloy ( $\alpha_{1}$ equal to zero), but the difference between the two conditions is rather small, as witnessed in the RDFs presented in Fig. 7.

Kinetic Monte Carlo (KMC) simulations at $500{ }^{\circ} \mathrm{C}$ were, furthermore, performed using four different atomic configurations obtained either from a random number generator, which correspond to a completely random alloy, or from the results (snapshots) of the thermodynamic MC simulations performed at 900, 800 , and $700{ }^{\circ} \mathrm{C}$, two of which correspond to the solution-treated samples in the experimental work. The KMC simulations were performed using Kawazaki dynamics (exchange between nearest neighbor atoms) assuming that the kinetics of $\mathrm{Fe}$ and $\mathrm{Cr}$ is the same and that the diffusion coefficient is about $10^{-17} \mathrm{~cm}^{2} / \mathrm{s}$. Although this is a fairly coarse estimate and a simple model for the kinetic process in real samples, it is considered to be appropriate to generate a qualitative view.

Figure 8 shows the atomic SRO parameter as a function of distance for the samples aged for 100 and $1000 \mathrm{~h}$ in the KMC simulations. The difference after aging between the four different initial conditions is very small, but a slight difference could be noticed, especially after $100 \mathrm{~h}$. The SRO parameter curves are slightly offset from each other with the random initial condition being the bottom-most curve and the $700{ }^{\circ} \mathrm{C}$ initial condition being the top-most curve. Furthermore, the point where the SRO parameter changes sign from positive to negative gives an indication of the effective size of the decomposed domains. It can be seen that the $700{ }^{\circ} \mathrm{C}$ initial condition has the largest domains and that the domain size after aging decrease with increasing randomness in the initial atomic configuration. Although the differences are noticeable, it is far from obvious. For the time being, we do not know the reason for this rather large difference between the experiments and the KMC simulations. There is a wide range of possibilities, starting from the simplified model of atomic diffusion in the KMC simulations and the difficulty in comparing the sharp atomistic simulations and the experimentally $3 \mathrm{D}$ reconstructed data, where the 

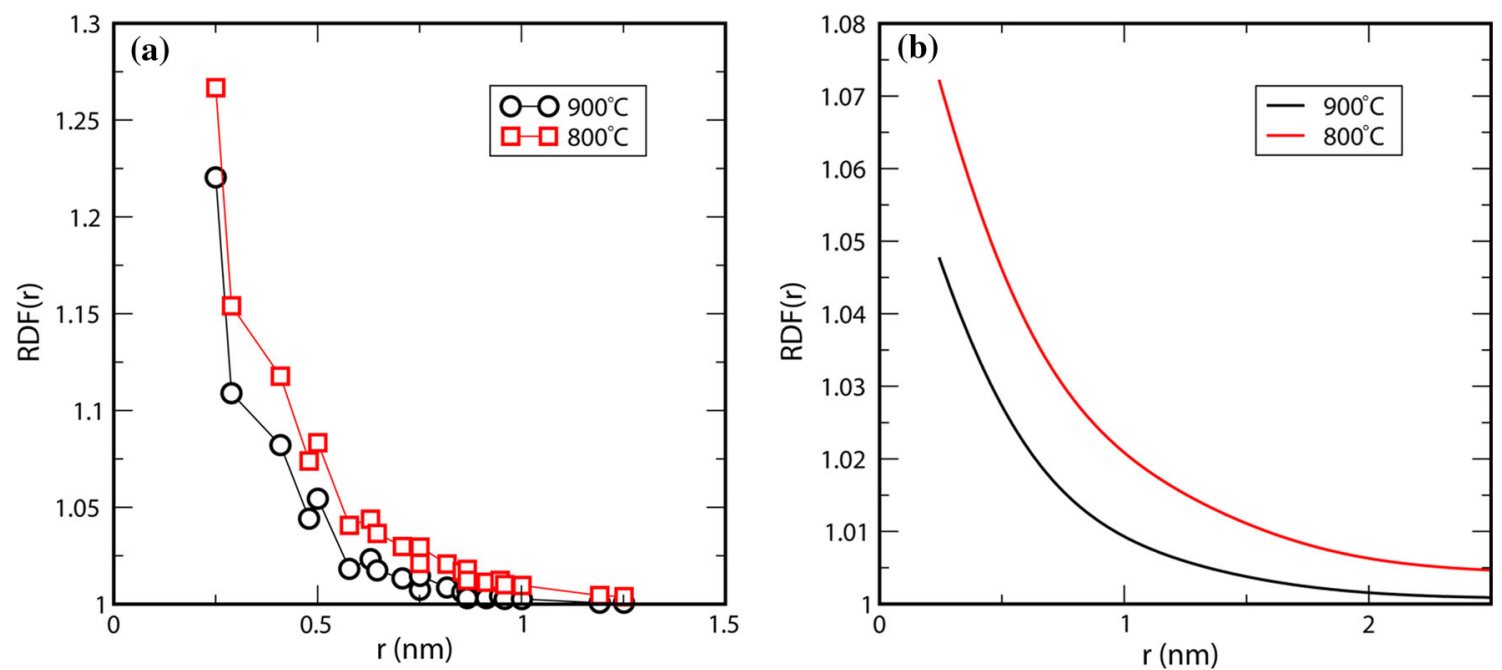

Figure 7 Radial distribution functions (RDFs) from thermodynamic Monte Carlo simulations a sharp RDFs b RDFs after Gaussian smearing, to be compared with the experimental RDFs in Fig. 3.

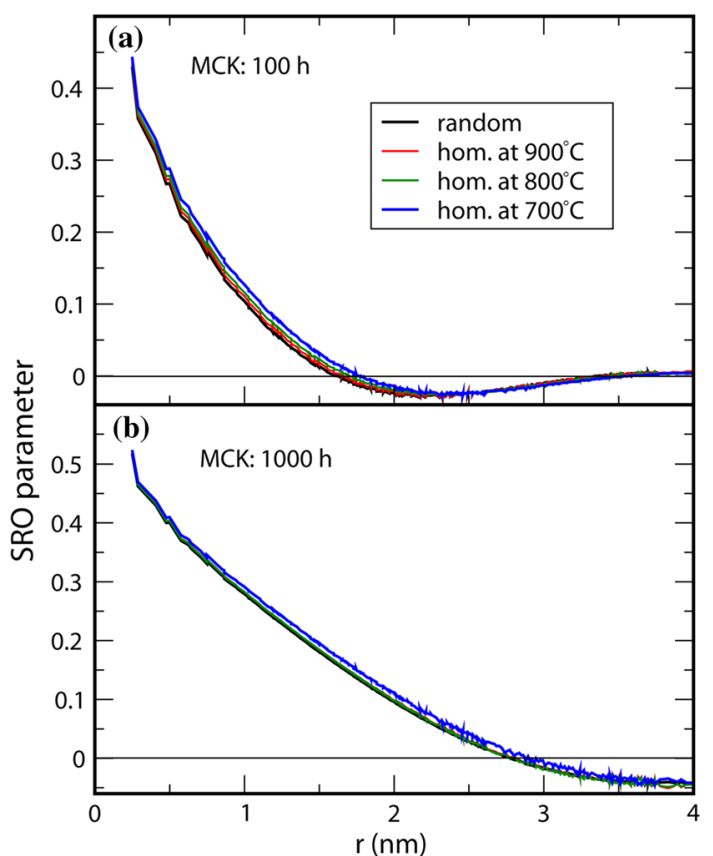

Figure 8 Atomic short range order parameter with radial distance for $\mathrm{Fe}_{53.5} \mathrm{Cr}_{46.5}$. a $100 \mathrm{~h}$ aging at $500{ }^{\circ} \mathrm{C}$ for different initial conditions b $1000 \mathrm{~h}$ aging at $500{ }^{\circ} \mathrm{C}$ for different initial conditions.

atoms are somewhat displaced from their exact positions in the lattice, and where about $63 \%$ of the atoms are missing due to the limited detection efficiency. We would, however, like to point out a slight difference in the morphology of the KMC results. Figure 9 shows snapshots of the different initial alloy conditions after aging for $1000 \mathrm{~h}$ at $500{ }^{\circ} \mathrm{C}$ and a qualitative difference between the initial conditions is indicated. The more random initial conditions (from Fig. 9a to d) appear to have more interconnected and "dense" Cr-rich regions (blue). The interconnectivity was, therefore, quantified using iso-concentration surfaces, but no clear tendency could be observed, partially because of the slight difference in wavelength and amplitude between the conditions, which complicates the analyses. Though no conclusion about the difference in nanostructure morphology can be drawn, what is clear is that, at present, the simplified modeling presented here is not able to capture the pronounced effect of solution treatment temperature on decomposition kinetics that has been found in the experiments in this work and also in prior experimental work [17, 18]. The modeling, however, qualitatively shows that the atomic SRO accumulated during the solution treatment can lead to different phase decomposition behaviors during subsequent aging inside the miscibility gap. More investigations on this matter are needed.

\section{Implications of findings on structural modeling and embrittlement}

The observed large effect of solution treatment on the phase decomposition kinetics, and its possible relation to the initial $\mathrm{Cr}$ clustering and the different nanostructure morphology, implies that this must be considered in structural modeling of this phenomenon. Furthermore, a proper control of the initial structure could improve structural integrity of components that are exposed to service conditions, where 
Figure 9 Kinetic Monte

Carlo simulations of alloy

$\mathrm{Fe}_{53.5} \mathrm{Cr}_{46.5}$ aged $1000 \mathrm{~h}$ at $500{ }^{\circ} \mathrm{C}$, starting from different initial conditions; from, random atomic configuration, to atomic SRO as calculated by thermodynamic Monte Carlo at 900, 800 and $700{ }^{\circ} \mathrm{C}$. Blue represents $\mathrm{Cr}$ and white represents $\mathrm{Fe}$ atoms. a random initial condition, b $900{ }^{\circ} \mathrm{C}$ initial condition, c $800^{\circ} \mathrm{C}$ initial condition, and $\mathbf{d} 700{ }^{\circ} \mathrm{C}$ initial condition. Simulation box is $100 \times 100 \times 100$ for the cubic (2-atom) unit cell, which equals to a $25.6 \mathrm{~nm}$ cube. (a) random initial condition

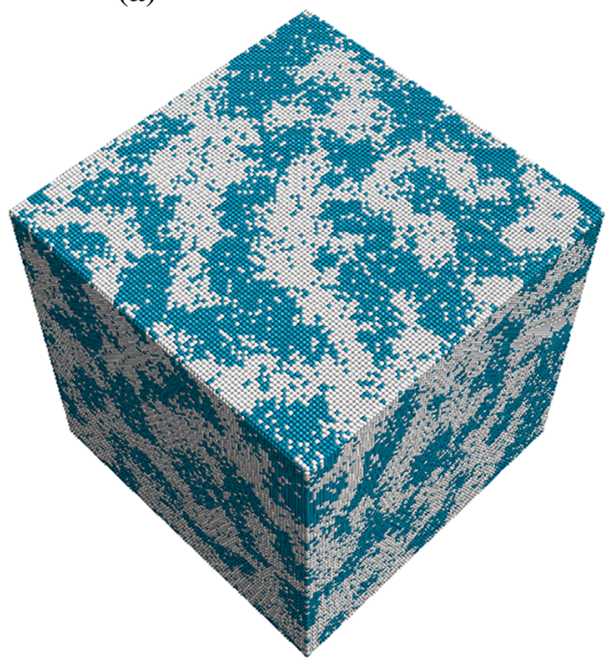

(c) $800^{\circ} \mathrm{C}$ initial condition

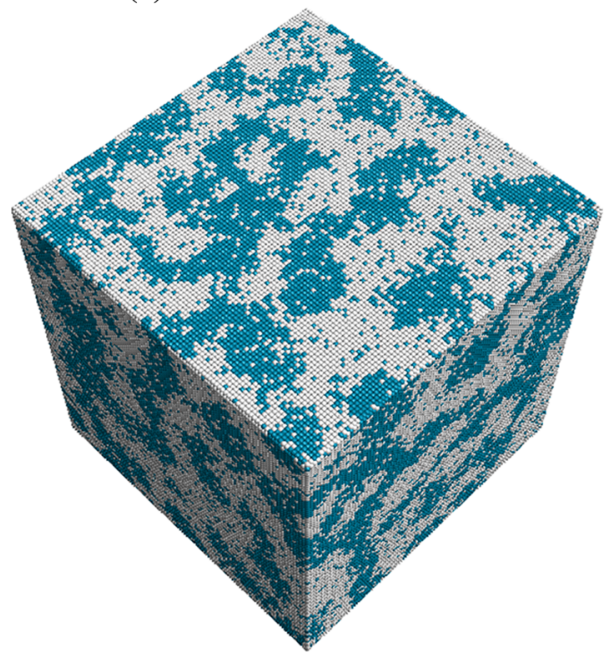

(b) $900^{\circ} \mathrm{C}$ initial condition

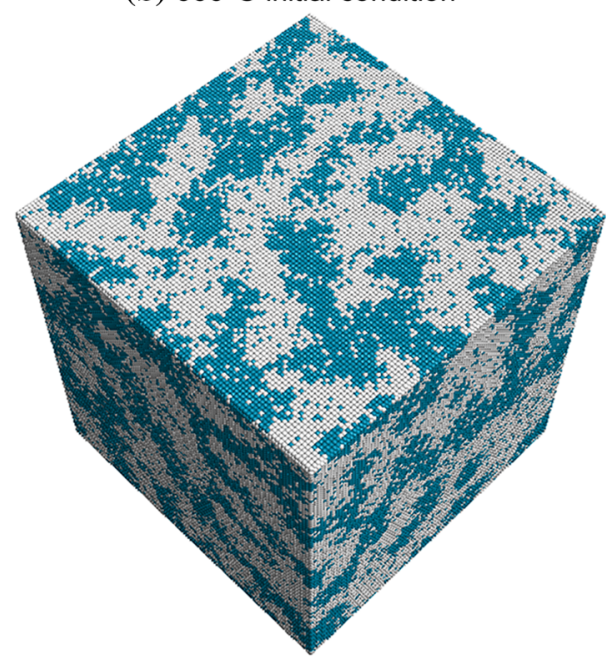

(d) $700^{\circ} \mathrm{C}$ initial condition

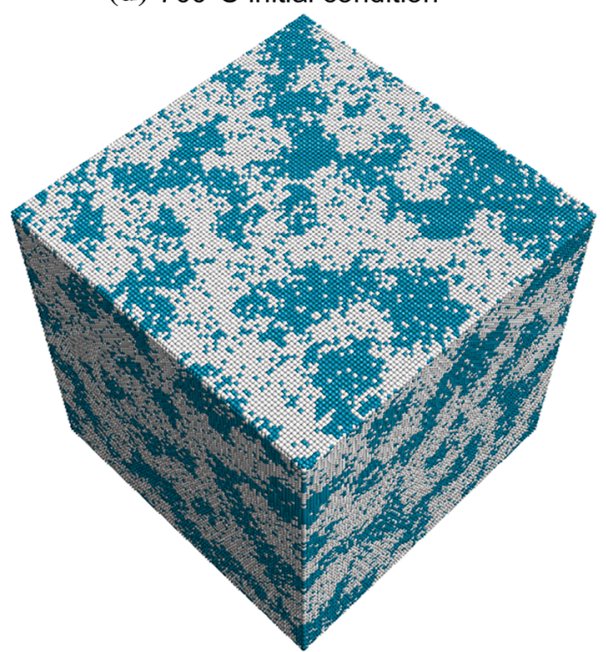

the $475{ }^{\circ} \mathrm{C}$ embrittlement would occur. The understanding of the initial structure and its effect on the subsequent aging is, however, hampered by the difficulty in studying the initial concentration fluctuations. So far, only a limited number of techniques, such as Mössbauer spectroscopy [32, 33], diffuse neutron scattering $[22,23]$ and atom probe tomography in this work and in Zhou et al. [24, 25], have been applied successfully for the investigation of the initial structure. Theoretically, there are a few viable methods to simulate the subsequent phase decomposition. $\mathrm{KMC}$ has been demonstrated in this work and the other main approach is phase-field modeling (see [25]). These two techniques are fundamentally different, being either atomistic (KMC) or continuum (phase-field) approaches. This implies, for instance, that clustering cannot be handled by the continuum approach, whereas it is difficult to treat large systems and multicomponent alloys in the atomistic approach. Hence, possibly, the best solution may be a multi-scale approach, where the different aspects of phase decomposition can be considered in a hierarchic modeling scheme.

\section{Conclusions}

- Cr clustering after solution treatments above the miscibility gap is found by atom probe tomography in an Fe-46.5 at.\% $\mathrm{Cr}$ alloy. The clustering is pronounced at $800{ }^{\circ} \mathrm{C}$, but decreases significantly with increasing temperature to $900{ }^{\circ} \mathrm{C}$. 
- The solution treatment plays a critical role for the kinetics of spinodal decomposition during subsequent aging at $500{ }^{\circ} \mathrm{C}$; the amplitude of decomposition is about 20 at.\% larger after $1000 \mathrm{~h}$ aging for the $800{ }^{\circ} \mathrm{C}$ initial condition compared with the $900{ }^{\circ} \mathrm{C}$ initial condition.

- Thermodynamic Monte Carlo simulations showed that there is a difference in atomic short range order between the different solution treatment temperatures. Furthermore, kinetic Monte Carlo simulations of the aging process demonstrated that the initial difference in atomic configurations gives a difference in aging kinetics, although the effect was much less pronounced compared with the experiments.

- For predictive modeling of spinodal decomposition kinetics, it is necessary to implement a modeling strategy that properly accounts for a non-random initial structure. However, first of all, the different physical effects contributing to the effect of the initial structure on phase decomposition must be disentangled.

\section{Acknowledgements}

This work was performed within the VINN Excellence Center Hero-m.

Funding This study was funded by Vinnova, the Swedish Governmental Agency for Innovation Systems, Swedish industry, KTH Royal Institute of Technology and Erasmus Mundus Tandem.

\section{Compliance with ethical standards}

Conflict of Interest The authors declare that they have no conflict of interest.

Open Access This article is distributed under the terms of the Creative Commons Attribution 4.0 International License (http://creativecommons.org/ licenses/by/4.0/), which permits unrestricted use, distribution, and reproduction in any medium, provided you give appropriate credit to the original author(s) and the source, provide a link to the Creative Commons license, and indicate if changes were made.

\section{References}

[1] Hillert M (1961) A solid-solution model for inhomogeneous systems. Acta Met 9:525

[2] Cahn JW (1961) On spinodal decomposition. Acta Met 9:795

[3] Cahn JW (1963) Hardening by spinodal decomposition. Acta Met 11:1275

[4] Thuvander M, Zhou J, Odqvist J, Hertzman S, Hedström P (2012) Observations of copper clustering in a $25 \mathrm{Cr}-7 \mathrm{Ni}$ super duplex stainless steel during low-temperature aging under load. Phil Mag Lett 92(7):336

[5] Hedström P, Huyan F, Zhou J, Wessman S, Thuvander M, Odquist $\mathrm{J}$ (2013) The $475^{\circ} \mathrm{C}$ embrittlement in $\mathrm{Fe}-20 \mathrm{Cr}$ and $\mathrm{Fe}-20 \mathrm{Cr}-\mathrm{X}(\mathrm{X}=\mathrm{Ni}, \mathrm{Cu}, \mathrm{Mn})$ alloys studied by mechanical testing and atom probe tomography. Mater Sci Eng A 574:123

[6] Pareige C, Novy S, Saillet S, Pareige P (2011) Study of phase transformation and mechanical properties evolution of duplex stainless steels after long term thermal ageing (>20 years). J Nucl Mater 411:90

[7] Bonnet S, Bourgoin J, Champredonde J, Guttmann D, Guttmann M (1990) Relationship between evolution of mechanical properties of various cast duplex stainless steels and metallurgical and aging parameters: outline of current EDF programmes. Mater Sci Technol 6:221

[8] Cook I (2006) Materials research for fusion energy. Nature Mater 5:77

[9] Hedström P, Baghsheikhi S, Liu P, Odqvist J (2012) A phase-field and electron microscopy study of phase separation in Fe-Cr alloys. Mater Sci Eng A 534:552

[10] Soriano-Vargas O, Avila-Davila EO, Lopez-Hirata VM, Cayetano-Castro N, Gonzalez-Velazquez JL (2010) Effect of spinodal decomposition on the mechanical behavior of $\mathrm{Fe}-$ Cr alloys. Mater Sci Eng A 527(12):2910

[11] Martínes E, Senninger O, Fu CC, Soisson F (2012) Decomposition kinetics of $\mathrm{Fe}-\mathrm{Cr}$ solid solutions during thermal aging. Phys Rev B 86:224109

[12] Pareige C, Roussel M, Novy S, Kuksenko V, Olsson P, Domain C, Pareige P (2011) Kinetic study of phase transformation in a highly concentrated $\mathrm{Fe}-\mathrm{Cr}$ alloy: Monte Carlo simulation versus experiments. Acta Mater 59:2404

[13] Huston EL, Cahn JW, Hilliard JE (1966) Spinodal decomposition during continuous cooling. Acta Met 14:1053

[14] Hedin M, Massoud JP, Danoix F (1996) Influence of the quenching rate on the spinodal decomposition in a duplex stainless steel. J Phys 6:235 
[15] Carmesin HO, Heermann HW, Binder K (1986) Influence of a continuous quenching procedure on the initial stages of spinodal decomposition. Zeitschr Phys B 65(1):89

[16] Lemoine C, Fnidiki A, Danoix F, Hedin M, Teillet J (1999) Mössbauer and atom probe studies on the ferrite decomposition in duplex stainless steels caused by the quenching rate. J Phys 11:1105

[17] Vintaykin YZ, Dmitriyev VB, Kolontsov VY (1969) The influence of heat treatment on the rate of separation of $\mathrm{Fe}-\mathrm{Cr}$ solid solutions. Fiz Met Metalloved 27:1131

[18] LaSalle JC, Schwartz LH (1986) Further studies of spinodal decomposition in Fe-Cr. Acta Met 34:989

[19] Lavrentiev MY, Drautz R, Nguyen-Manh D, Klaver TPC, Dudarev SL (2007) Monte Carlo study of thermodynamic properties and clustering in the bcc $\mathrm{Fe}-\mathrm{Cr}$ system. Phys Rev B 75:014208

[20] Ruban AV, Korzhavyi PA, Johansson B (2008) First-principles theory of magnetically driven anomalous ordering in bcc Fe-Cr alloys. Phys Rev B 77:094436

[21] Ruban AV, Razumovskiy VI (2012) First-principles based thermodynamic model of phase equilibria in bcc $\mathrm{Fe}-\mathrm{Cr}$ alloys. Phys Rev B 86:174111

[22] Mirebeau I, Hennion M, Parette G (1984) First measurement of short-range-order inversion as a function of concentration in a transition alloy. Phys Rev Lett 53:687

[23] Mirebeau I, Parette G (2010) Neutron study of the short range order inversion in $\mathrm{Fe}_{1-\mathrm{x}} \mathrm{Cr}_{\mathrm{x}}$. Phys Rev B 82:104203

[24] Zhou J, Odqvist J, Höglund L, Thuvander M, Barkar T, Hedström P (2014) Initial clustering-a key factor for phase separation kinetics in $\mathrm{Fe}-\mathrm{Cr}$-based alloys. Scripta Mater $75: 62$
[25] Zhou J, Odqvist J, Ågren J, Ruban AV, Thuvander M, Xiong W, Olson GB, Hedström P (2015) Direct atom probe tomography observations of concentration fluctuations in $\mathrm{Fe}-\mathrm{Cr}$ solid solution. Scripta Mater 98:13

[26] Xiong W, Hedström P, Selleby M, Odqvist J, Thuvander M, Chen Q (2011) An improved thermodynamic modeling of the $\mathrm{Fe}-\mathrm{Cr}$ system down to zero Kelvin coupled with key. Calphad 35:355

[27] Brenner SS, Camus PP, Miller MK, Soffa WA (1984) Phase separation and coarsening in $\mathrm{FeCrCo}$ alloys. Acta Met 32:1217

[28] Miller MK (2000) Atom probe tomography: analysis at the atomic level, 1st edn. Kluwer Academic/Plenum Publishers, New York

[29] Zhou J, Odqvist J, Thuvander M, Hedström P (2013) Quantitative evaluation of spinodal decomposition in $\mathrm{Fe}-\mathrm{Cr}$ by atom probe tomography and radial distribution function analysis. Microsc Microanal 19:665

[30] Reinhard L, Robertson JL, Moss SC, Ice GE, Zschack P, Sparks J (1992) Anomalous-x-ray-scattering study of local order in bcc $\mathrm{Fe}_{0.53} \mathrm{Cr}_{0.47}$. Phys Rev B 45:2662

[31] Blavette D, Grancher G, Bostel A (1988) Statistical analysis of atom-probe data (I): derivation of some fine-scale features from frequency distributions for finely dispersed systems. J Phys 49:433

[32] Dubiel SM, Cieslak J (2011) Short-range order in iron-rich $\mathrm{Fe}-\mathrm{Cr}$ alloys as revealed by Mössbauer spectroscopy. Phys Rev B 83(18):180202

[33] Dubiel SM, Zukrowski J (2013) Phase-decomposition-related short-range ordering in an $\mathrm{Fe}-\mathrm{Cr}$ alloy. Acta Mater 61:6207 